\title{
COMO ABORDAR OS EFEITOS DE UM TRATAMENTO OFERTADO EM UM SERVIÇO DE PSICANÁLISE NO ÂMBITO PÚBLICO
}

Claudia Maria de Sousa Palma, Luciane Loss Jardim, Iza Maria de Oliveira

\begin{abstract}
Claudia Maria de Sousa
Palma

Psicanalista, profa. doutora do Departamento de Psicologia da Universidade Federal de Santa Maria/RS, pósdoutora (Unicamp) e pesquisadora do Laboratório de Psicopatologia Fundamental do Departamento de Psicologia Médica e Psiquiatria da Unicamp.

Luciane Loss Jardim Psicanalista, membro

RESUMO: A inserção da psicanálise no âmbito público convida ao estabelecimento de novos dispositivos, próprios à condução de um tratamento psíquico, isto é, à criação de procedimentos que respondam a uma clientela específica no cenário público. Nessa via, propomos uma técnica de avaliação, orientada pelos princípios do método psicanalítico, visando abordar os efeitos terapêuticos e analíticos desses procedimentos clínicos sobre a subjetividade. A técnica de avaliação foi utilizada em uma proposta de tratamento ofertada a adultos atendidos pelo Serviço de Psicanálise do Ambulatório de Psiquiatria do Hospital das Clínicas da Unicamp. Com o estudo, objetivamos destacar a pertinência desta técnica de avaliação em uma prática clínica exercida sob novos dispositivos em instituições públicas.
\end{abstract} da Associação Psicanalítica de Porto Alegre (Appoa), doutora em Psicologia Clínica PUC/SP e pesquisadora do Laboratório de Psicopatologia Fundamental do Departamento de Psicologia Médica e Psiquiatria da Unicamp.

Iza Maria de Oliveira Psicanalista, presidente da Associação Espaço Psicanalítico (AEP), doutoranda em Psicologia Clínica PUC-SP. Autora de Fragmentos amorosos (Ed. Unijui).

Palavras-chave: tratamento psicanalítico, psicologia hospitalar, avaliação qualitativa, orientação lacaniana.

ABSTRACT: How to take the effects of a treatment offered in a Department of Psychoanalysis in the public institution. The insertion of psychoanalysis in the public establishment invites for the new mechanisms, in order to drive to appropriate psychological treatment, i.e., the definition of procedures to respond to a specific public scenario customer. Following this path, we propose an evaluation technique, guided by the principles of the psychoanalytic method, looking for the therapeutic and analytical effects in the clinical procedures above/on subjectivity. The evaluation technique was used in a proposal for a treatment offered to adults by the Psychoanalysis Service of the Psychiatry Ambulatory of the Clinical Hospital of Unicamp. This study aims to highlight the relevance of this technique in a clinical evaluation conducted under new arrangements in public institutions.

Keywords: psychoanalytic treatment, psychology hospital, qualitative assessment, Lacanian orientation. 


\section{INTRODUÇÃO}

A questão que motiva este trabalho pode ser assim formulada: é notória a utilização da psicanálise nas esferas públicas de saúde, assim como também o é a dificuldade ou, para alguns, a impossibilidade de se mostrarem os resultados analíticos, já que esses tangenciam o mais particular de cada um, muitas vezes inominável, bem como requerem um tempo cronológico para se estabelecerem, que quase nunca corresponde às condições de tempo da instituição.

No que tange ao campo da pesquisa e avaliação em psicanálise, podemos destacar dois modelos, independentes entre si, propostos pelas comunidades psicanalítica e acadêmica. O primeiro está baseado exclusivamente em critérios psicanalíticos, como a indissociabilidade entre procedimento de investigação, dispositivo e método de pesquisa, exigindo-se o estudo dos processos inconscientes na modalidade de estudo de caso. Já o segundo é um modelo de pesquisa em que psicanalistas, através de outros métodos que não os próprios da psicanálise, ambicionando satisfazer critérios científicos exteriores à própria experiência clínica, objetivam um intercâmbio de ideias e provas com outras disciplinas sobre a eficácia terapêutica da psicanálise.

Nesta perspectiva, destacam-se os postulados de Fonagy (2003), que presidiu a Comissão Permanente de Pesquisa (Standing Research Committee) da IPA (International Psychoanalitical Association), defendendo uma sistematização dos conhecimentos de base, de modo a propiciar uma integração com as novas ciências da mente, bem como gerar a possibilidade de comunicação com outros cientistas acerca das descobertas psicanalíticas, podendo-se, inclusive, evidenciar a eficácia do tratamento.

Com efeito, apresentamos nosso trabalho de pesquisa como um terceiro modelo, ou seja, propomos criar um dispositivo que responda à especificidade da clínica psicanalítica, como também permita a transmissão de sua prática. Tratase de um dispositivo psicanalítico para a abordagem dos efeitos do tratamento em pacientes adultos, atendidos pelo Serviço de Psicanálise do Ambulatório de Psiquiatria do Hospital das Clínicas da Unicamp.

O tratamento em questão é estabelecido a partir de novos dispositivos, como gratuidade, condução clínica proposta por estagiários em formação inicial, tempo limitado a priori para o tratamento e, também, de permanência com atendimento por um mesmo estagiário, encaminhamento preponderantemente médico dos casos, * e solicitações por trocas de informações sobre o paciente em equipe interdisciplinar. Enfim, traz especificidades do âmbito público à clínica psicanalítica, as quais incluem o próprio locus do Serviço de Psicanálise, um hospital geral e um ambulatório de psiquiatria.

Assim, pretendemos formalizar uma variação da clínica, isto é, um fazer construído a partir das especificidades do cenário institucional e público de 
saúde, distinto do panorama original em que se desenvolveu a terapêutica psicanalítica, mas que não pode deixar de se reconhecer na especificidade da obra freudiana.

Desse modo, duas interrogações dirigem o presente trabalho:

a) As propostas clínicas criadas em resposta às especificidades institucionais alcançam os objetivos descritos pela metapsicologia psicanalítica no que tange à finalidade de um tratamento?

b) Como formalizar os efeitos que tangenciam o singular de cada um, no sentido de poder elevá-los a uma categoria propiciadora da qualificação de uma prática psicanalítica?

Considerando as respostas como o objetivo final de nosso estudo, o que ora apresentamos é apenas o início. A partir de um estudo piloto, com o inusitado de um caso, destacaremos o método criado para a coleta e análise dos dados, o qual se diferencia das modalidades de avaliação sustentadas em parâmetros exteriores à experiência do tratamento.

Assim, propomos um método que está ancorado na articulação entre a demanda pela qualificação de uma prática na instituição e a necessidade de se guardar a singularidade da clínica, que é o fazer psicanálise.

\section{SOBRE A CLÍNICA PSICANALÍTICA NO ÂMBITO PÚBLICO}

A clínica psicanalítica é constituída por uma metapsicologia e uma prática de intervenção psíquica, que hoje se encontram bastante difundidas no âmbito da saúde pública, em seus diferentes níveis: primário, secundário e terciário.

O hospital geral (terciário), junto com os ambulatórios de saúde mental, centros de convivência, serviços residenciais e centros de atenção psicossocial, compõem a rede de atenção à saúde mental. Ele cumpre a função de responder às complexidades clínicas que os outros serviços não abarcam, além de possuir a especificidade de formação (residências e especializações) de profissionais da saúde.

Em consonância com as diretrizes da política de saúde mental (BRASIL, 2005), o ambulatório de psiquiatria do Hospital das Clínicas da Unicamp propõe a diversidade de intervenções, estando a psicanálise incluída na terapêutica de pacientes com transtornos mentais graves. Entretanto, o ambulatório também recebe pacientes clínicos, neuróticos em sua maioria, encaminhados pela interferência do psiquismo no tratamento de patologias orgânicas tratadas em outras clínicas do hospital.

É oportuno destacar que o método proposto tangenciou a clínica das neuroses, compreendendo pacientes com queixas vinculadas ao fracasso com a vida afetiva, social e/ou profissional encaminhados, de início, pela clínica médica e, depois, pela avaliação psiquiátrica. 
Quanto à organização do Serviço, quem recebe o paciente e será o responsável pelo seu tratamento é o profissional-estagiário. A oferta clínica, a princípio, é de um ano, podendo se renovar por mais um, com outro profissional, e os atendimentos são supervisionados por analistas experientes.

Sob essa nomeação — clínica psicanalítica — se reúnem profissionais, psicólogos e psiquiatras, associados às escolas psicanalíticas que, por um lado, guardam diferenças substanciais quanto à condução do tratamento e compreensão teórica do aparelho psíquico e, por outro, se unificam pela oferta de uma escuta e uma intervenção pela palavra que possam alterar a relação do sujeito com seu inconsciente.

Na nossa perspectiva, é importante marcar tal configuração, pois, se existem diferenças teóricas de entrada, de meio e fim de uma análise, a partir das distintas orientações psicanalíticas, não se diverge em essência no efeito que toca a relação do sujeito com seu inconsciente.

Não se diz "esse é um efeito kleiniano, esse é freudiano, ou esse é lacaniano”, pois os conceitos fundamentais como pulsão, inconsciente, transferência e repetição orientam a prática psicanalítica, permitindo o unificador da nomeação clínica psicanalítica.

O interesse pela psicanálise no âmbito da saúde pública tem motivado importantes trabalhos, centrados na viabilidade da clínica psicanalítica fora do modelo liberal privado. Tais estudos convergem para a pertinência do tratamento na instituição, apresentando as especificidades clínicas e os respectivos dispositivos criados - manejo de sessões por semana e horários, como destaca Figueiredo (1997); recursos ao estabelecimento da privacidade nos atendimentos em enfermarias, conforme sugere o estudo de Moretto (2001) e, também, propostas clínicas para manejar o tempo de tratamento, de acordo com Bueno e Pereira (2002).

Com efeito, nosso estudo parte desse exercício de estabelecimento da clínica, isto é, da legitimidade dessa inserção, alinhando-se àqueles que se ocupam em clarificar as condições de término de um tratamento.

Esse interesse em Lacan (1973a/1985) encontra eco quando ele se propõe a analisar o ofício do discurso analítico, destacando que o objetivo não é torná-lo oficial — se trata de descobri-lo e torná-lo oficiante, isto é, operante pela via da transmissão. Decerto essa é a discussão mais difícil com relação à psicanálise, porque uma coisa é a experiência analítica, e outra é falar sobre ela ou mostrá-la.

Aproximando-se dessa seara, a hiância entre a singularidade da experiência, impossível de se universalizar, e a necessidade de parâmetros universais para a comunicação de uma experiência no discurso científico, tem sido convocada a legitimar a resposta negativa do campo analítico perante as demandas de ava- 
liação de resultados, denotando um lugar de exclusão da psicanálise quando a referência é algo do universal.

De fato, o método de avaliação de resultados é inadequado à experiência psicanalítica, considerando as categorias de avaliação utilizadas, tais como: avaliação de melhora sintomática e das disfunções na vida diária; avaliação da intervenção em psicopatologias específicas, como, por exemplo, alcoolismo, esquizofrenia e ansiedade, nas quais os parâmetros de medida recaem sobre o controle e/ou a diminuição sintomática e melhor adaptação social; e avaliação comparativa de técnicas, como individual e grupal, breve em relação a tempo longo. ${ }^{1}$

Por outro lado, na atualidade, com uma generalização das práticas da escuta e uma concepção de cura pela palavra muitas vezes banalizada, sair desse lugar de exclusão da avaliação, criando condições para a análise da prática a partir dos efeitos, permite a transmissão da razão da psicanálise como proposta de tratamento na saúde pública, ainda mais se considerarmos a diversidade de operações metodológicas que se têm materializado com a clínica psicanalítica nesse contexto.

Nessa via de análise da prática, alinhados com as variáveis da experiência psicanalítica, aparecem os estudos de caso, com discussões conceituais e técnicas quanto, por exemplo, ao valor da especificidade da relação transferencial para o tratamento. Aparecem também interessantes trabalhos teóricos que discutem a inadequação dos parâmetros padronizados para a avaliação da prática analítica, já que o tratamento visa o singular de cada um, destacando a necessidade legítima de uma avaliação por "procedimentos internos” à experiência psicanalítica, como propõe Eizirik (2001).

Entretanto, esse modelo não permite a construção de parâmetros favorecedores à qualificação e transmissão de uma prática no sentido amplo, isto é, caracterizador de um Serviço.

Tramando nosso caminho do meio com o tratamento psicanalítico, independente do contexto, pretende-se uma experiência subjetiva que cause um reposicionamento no paciente frente à desordem de que se queixa. Espera-se, com o tratamento, uma responsabilidade inédita do sujeito, responsabilidade pelo seu modo de sofrer e de amar. Para tanto, o tratamento requer arte e técnica.

A arte da psicanálise, a singularidade de seu proceder, estaria no meio desse percurso, no que se produz e se decompõe a cada sessão, dependendo, sobretudo, do encontro analista-analisante ou, de outra forma, do surgimento do inconsciente — como a arte, impossível de formalizar.

Fazendo borda a essa produção, tratando-a, temos a técnica, isto é, o estabelecimento de procedimentos específicos e necessários à operação da arte, cuja

\footnotetext{
${ }^{1}$ Fonte de consulta bibliográfica: Medline, Lilacs, Scielo e BVS.
} 
nomeação mais adequada seria um método, considerando a apropriação corrente do termo técnica, vinculado a um proceder prévio e repetitivo — portanto inadequado ao fazer psicanalítico.

Assim, buscamos um método que permita qualificar o início do processo e o seu final. Nessa vertente, Freud (1913/1987), quando se propunha a pensar a prática psicanalítica, encontrava no jogo de xadrez um indicador da experiência, no sentido de só podermos codificar as aberturas e os finais, sendo o meio impossível de codificação.

Nesse cenário, se utilizarmos um método de análise pertinente ao método de tratamento, poderemos codificar as condições iniciais e finais de uma experiência com a psicanálise para torná-la transmissível, indicando a diferença de manejo com o sofrimento a que se propõe essa clínica quando comparada a outras formas de intervenção sobre o psiquismo, podendo, então, configurar um Serviço de Psicanálise.

Não menos importante, a análise crítica dos limites e alcances do fazer psicanálise na instituição permite que se reflita sobre a teoria e as variações no exercício da prática, acrescentando novos subsídios metapsicológicos e clínicos à delimitação da psicanálise na instituição.

\section{SOBRE O MÉTODO PSICANALÍTICO: O INVARIÁVEL NA CLÍNICA}

Lacan, abordando a psicanálise a partir de sua não inscrição na ciência ou na religião, indaga sobre a práxis:

“O que é uma práxis? Parece-me duvidoso que este termo possa ser considerado como impróprio no que concerne à psicanálise. É o termo mais amplo para designar uma ação realizada pelo homem, qualquer que ela seja, que o põe em condição de tratar o real pelo simbólico...” (LACAN, 1964a/1998, p.14)

Considerando que o analista, para tratar o real, não pesquisa, não procura como o cientista, nem tampouco pretende ir ao encontro do "já achado", o que está sempre por trás atingido por um esquecimento, como o religioso, ao que visa o analista quando se propõe à abordagem do real pelo simbólico?

Resgatando Picasso, no mesmo texto, quando indagado sobre os motivos de sua produção artística, ou seja, de onde buscava inspiração, Lacan toma emprestada a resposta do pintor para qualificar sua prática enquanto analista: “eu não procuro, acho". Tal qual o pintor, o "acho" se situa em um encontro não com algo esquecido, atrás, mas com um inusitado, nomeado por Lacan de encontro com o real. 
Esse encontro se recobre, no instante posterior, por um simbólico: Picasso com sua produção artística, o neurótico com sua mesmice sintomática. Assim, a análise pretende ofertar uma experiência em que esse encontro possa receber uma abordagem própria, outra resposta que não aquela apresentada pela via da compulsão à repetição. Tal operação se faz possível, pelo simbólico, na medida que a compulsão se articula à sintaxe que faz funcionar a rede de significantes, pedindo elaboração.

Desse modo, a repetição deve ser entendida como um movimento que, ao fixar uma identidade, é também diferencial como intrínseco ao funcionamento da linguagem, isto é, às leis do significante. Com efeito, quando um analista oferta o dispositivo da palavra - associação livre - e, através da transferência, promove a abertura do inconsciente, perpassando por todas as vicissitudes que tal trabalho impõe, espera causar no paciente outra forma de se haver com o real da incompletude, do impossível de se garantir, da frustração inerente, da morte certa.

Lembremos que operar com a palavra não é particularidade da psicanálise. Entretanto, operar de maneira radical com a palavra que traduz uma história desejante, tomada como índice da realidade psíquica do sujeito, é aonde reconhecemos o campo da psicanálise.

Esta é a "mágica" freudiana: conceder à palavra uma função ímpar, qual seja, transformar a realidade psíquica do sujeito, favorecendo a reinvenção da subjetividade. Em análise leiga, respondendo ao leitor imparcial, Freud resgata o lugar da palavra:

“...é um instrumento poderoso; é o meio pelo qual transmitimos nossos sentimentos a outros, nosso método de influenciar pessoas... as palavras podem fazer um bem indizível e causar terríveis feridas... originalmente a palavra foi magia - um ato mágico — e conservou muito de seu antigo poder.” (FREUD, 1926/1987, p.214)

Assim, a experiência psicanalítica consiste em causar uma fala específica que se constitui como tal a partir da transferência, endereçada ao analista como suposto-saber do mal-estar do sujeito. Nessa perspectiva, é base da pesquisa em psicanálise, não existindo uma construção teórica ou metodológica na exterioridade da experiência da transferência, pois ela é quem convida o sujeito do inconsciente a falar.

Portanto, qualquer análise da experiência do tratamento psicanalítico não pode prescindir da própria clínica, posto que o interesse se concentra em alterações na economia e na dinâmica inconscientes. 
Como desdobramento, considerando a perspectiva dos efeitos do tratamento, tais alterações incidirão no modo de o indivíduo agir. Entretanto, as diferenças externas, unicamente, não devem ser tomadas como indicadores exclusivos, já que nem toda mudança de atitude traduz alteração na dinâmica do inconsciente; também não há uma relação linear e "automática” entre mudança de posicionamento subjetivo e mudanças de comportamento/conteúdo.

Entre estes, há um tempo para que os efeitos de uma interpretação operem — tempo esse lógico, não cronológico — , contingente e não previsível. Essa configuração limitaria qualquer proposta de análise dos efeitos de um tratamento psicanalítico assentada numa análise de conteúdo/comportamento em si.

Com efeito, não é esse nosso interesse, qual seja, destacar mudanças de conteúdo/atitude como índices de efetividade de um tratamento psicanalítico. Considerando a experiência da transferência, nosso interesse se assenta no posicionamento do sujeito frente ao Outro e, por extensão, aos outros.

Nessa via, a operação analítica se realiza marcadamente sobre os efeitos do inconsciente no deslocamento das certezas no dito e nos atos do sujeito, assumindo, nesse lugar, a palavra ou ação do analista um valor interpretativo, causador de um deslocamento de sentido-posição do sujeito frente à vida.

Considerando esse como o campo operante da prática psicanalítica, o invariável, até onde se pode chegar com a implantação de dispositivos que respondam às novas contextualizações clínicas para a psicanálise, sem que se perca de vista o de que se trata com a prática psicanalítica?

\section{SOBRE O MÉTODO PROPOSTO: APRESENTAÇÃO DE UM CASO CLÍNICO}

O método proposto, portanto, espera formalizar o que se tem produzido com a experiência psicanalítica, num determinado recorte cronológico, considerando o campo do inconsciente. Como operar nesse campo de um lugar exterior à experiência mesma do tratamento é a nossa questão primeira.

Lacan, sobre a transferência, delimita: "a ausência de um analista no horizonte, não destitui a presença dos efeitos de transferência exatamente estruturáveis como o jogo da transferência na análise" (LACAN, 1964b/1998, p.120). Ainda que a pesquisadora não fosse também a analista do paciente, se este experimentou o jogo da transferência, ela (a analista-pesquisadora) poderia atualizá-lo, presentificar seus efeitos, no encontro da entrevista.

Assim hipotetizamos a viabilidade de nosso método. Por meio de um modus operandi dirigido ao inconsciente, ofertando o dispositivo da associação livre ao estabelecimento de uma determinada forma de se dizer "familiar", enquanto lugar de escuta e intervenção, esperamos o surgimento da produção inconsciente. 
Com efeito, haveria uma transferência inicial não à analista, propriamente, mas ao discurso do inconsciente, em que um encontro prévio com a experiência analítica seria indispensável.

Como consequência, nossa hipótese seria de que, nos casos iniciais ou naqueles em que a experiência com o inconsciente não se estabeleceu, predominariam, nas entrevistas, atribuições universais de sentido sobre si, o médico, o mundo e/ou a expressão única da linguagem. O paciente se manteria na entrevista apenas pela transferência à instituição, sendo pouco diferenciada essa primeira entrevista de uma anamnese.

Dessa forma, nossa aposta em um método que contemple um analista ofertando os dispositivos específicos à prática clínica - convite à associação livre, escuta do excluído, forçamento na atitude de implicação do sujeito para com sua queixa, transferência ao saber do inconsciente - num modelo tangente à experiência do tratamento, pode abordar os efeitos dessa experiência sem descaracterizá-la.

Como enuncia Dunker (2006), a experiência psicanalítica, pensada sob a ótica da constituição, isto é, enquanto momento fundante de outras possibilidades reguladoras, diz respeito a uma sucessão de cortes. Cada sessão pode ser tomada como fonte de experiência com a clínica psicanalítica, com os efeitos que esta se propõe causar com o dispositivo da palavra sob transferência.

Essa perspectiva, sem dúvida, está em sintonia com as já destacadas particularidades do contexto institucional, permitindo a pesquisa no tempo possível ao paciente na instituição. O tratamento como uma série de experiências, não contínuas, porém articuláveis, gera a possibilidade de se verificarem e mostrarem os efeitos com a clínica psicanalítica, num determinado recorte temporal, ainda que o tratamento não se tenha findado, ou que outros e importantes efeitos possam aparecer num tempo posterior.

Por fim, nossa segunda questão diz respeito à ratificação do procedimento a ser utilizado a partir da experiência com um único caso, descrito a seguir. Elisa ${ }^{2}$ é encaminhada para a pesquisa sem a consideração do critério de entrada no estudo piloto, ${ }^{3}$ fato constatado depois do início da entrevista. ${ }^{4}$

A condição de já ter experimentado atendimento por um ano, estando ali devido à continuidade que demandava igual período, a princípio, retiraria Elisa do grupo para o estudo; por outro lado, sua inclusão, permitiu a verificação da

\footnotetext{
${ }^{2}$ Nome fictício.

${ }^{3}$ Ao estudo piloto interessava o caso-novo, ou seja, iniciante no Serviço de Psicanálise. O objetivo, nesse momento, era verificar a pertinência da entrevista enquanto meio de abordagem à organização discursiva do sujeito.

${ }^{4}$ As entrevistas foram gravadas e, posteriormente, transcritas em díade, isto é, inicial e final de cada paciente do estudo propriamente dito.
} 
nossa hipótese. Ou seja, a partir dessa contingência pudemos, por meio do cotejamento da produção de Elisa com a produção discursiva de 11 casos do estudo piloto, verificar nossa hipótese quanto à pertinência do método para a pesquisa em si, o que mostramos a seguir.

A entrevista tem início, como em todas as realizadas, com um convite à paciente para que fale de si. De pronto, Elisa se diz "impedida de fazer as coisas, por isso inútil”, comunicando seu diagnóstico orgânico ("asma”) e o concomitante psíquico ("depressão”): “tenho asma, então não posso fazer nada e fico com depressão”.

Nos momentos iniciais da entrevista, a paciente apresenta um discurso sobre si que parece utilizar perante qualquer profissional da saúde interessado em seu caso: "faz 11 anos que tenho asma e não consigo me curar... ${ }^{5}$ os médicos dizem que não posso fazer um monte de coisas e muitas pessoas não entendem e acham que sou vagabunda... às vezes tô melhor, às vezes fico mal, sabe, né, todo asmático tem depressão... já tentei o suicídio e foi na última tentativa que me mandaram pra cá” (psiquiatria e, depois, psicoterapia psicanalítica).

A técnica da associação livre convoca a palavra como meio de acesso às formações do inconsciente (ato falho, chiste, sintoma, sonho). As formações são tomadas como indicadores da ordem de funcionamento do sujeito. É assim que a realidade psíquica, objeto de intervenção, se apreende na emergência da fala, que surge sob a transferência e porta as formações do inconsciente, bem como nas ações prenhes de sentido.

Com efeito, cada realidade se funda e se define por um discurso. O inconsciente, com Lacan, é a soma dos efeitos da fala sobre um sujeito em que o mesmo se constitui pelos efeitos do significante (LACAN, 1964b/1998), atribuindo sentidos, construindo cadeias de significação que dirigem seu modo de ser no mundo.

Retornando ao caso, Elisa, nos momentos iniciais, ao revelar sua particularidade por meio da reprodução de um discurso científico, narra sua história de doença a partir de um lugar queixante-universal, indicando a ausência do laço - transferência - o qual cria a condição para o aparecimento dessa fala do inconsciente, à qual dirige o trabalho analítico.

Assim, desconsiderando os sentidos universais de sua narrativa, buscando o encontro com outro discurso, pergunto: “Elisa, o que você vem buscar com a sua psicoterapia?" (termo utilizado por ela). Após um curto silêncio associado a um olhar fixo para mim, fala: "tudo que eu quero fazer na minha vida parece que tem uma barreira que a doença não deixa... então são várias coisas que eu tento escapar, mas sempre tem alguma coisa no meio que me impede e isso me deixa com raiva, com ódio de mim mesma, eu me sinto uma inútil, um nada...

\footnotetext{
${ }^{5}$ Indicação de continuidade discursiva.
} 
eu tento ir pra um lado, ir pro outro, mas não consigo ver uma saída, parece que não existe uma saída... eu não aceito o que eu tenho, entendeu, porque eu sou uma pessoa assim, sabe, eu gosto de conversar, de falar, o tempo todo agitada, sabe, fazendo alguma coisa, só que acontece tudo isso, onde que vem aquela raiva porque eu sou o oposto disso de querer fazer uma coisa e não poder fazer e eu tenho que ficar parada... daí tem as coisas da infância, meu pai era alcoólatra... quantas vezes ele desejou que eu morresse... é muita coisa... minha mãe foi muito rígida...”.

Ao paciente solicitamos a fala sobre outra cena, cena que porta o inusitado de um sentido e de um afeto e que convida a uma re-colocação do sujeito frente ao Outro, ou seja, solicitamos os sentidos particulares, próprios, que denotem a inserção do sujeito no liame social. O discurso assim construído, isto é, sob um modo próprio de se narrar, funciona como um indicador importante do lugar frente às questões essenciais de vida e morte. Como consequência, com o tratamento, uma alteração de lugar deve se mostrar na organização discursiva.

Elisa responde à solicitação. De uma fala inicial sem sujeito, como que narrando algo em terceira pessoa ("todo asmático tem depressão”), Elisa passa a um discurso em primeira pessoa, no qual algo de outra cena desponta ("eu sou agitada, gosto de conversar, ... me deixa com raiva, com ódio”) sobre o universal de sua queixa ("asma e depressão") e a desconcerta ("eu sou o oposto — agitada - e tenho que ficar parada”).

A sintaxe, segundo Lacan (1973b), é pré-consciente, mas o que escapa ao sujeito é que sua sintaxe está em relação com a reserva inconsciente. É essa estrutura - o jogo combinatório operando em sua espontaneidade - que dá seu estatuto ao inconsciente, isto é, que nos garante "que há sob o termo inconsciente algo de qualificável, de acessível, de objetivável” (LACAN, 1964b, p.26), e quando o sujeito conta sua história, o inconsciente age, latente, comanda essa sintaxe e a faz cada vez mais cerrada em torno de um núcleo.

O qualificável, o acessível surgiria no nível do sujeito da enunciação, na fala que manca, carrega uma interjeição, uma invocação, uma dúvida. Daí Freud colocar sua certeza somente na constelação de significantes, tal como eles resultam da narrativa, do comentário, da associação, pouco importando a retratação (LACAN, 1964c).

No discurso de Elisa, a abertura da significância se faz possível, denotando a presença do material necessário ao trabalho analítico, por exemplo, com "barreira que a doença não deixa, tem alguma coisa no meio que me impede e isso me deixa com raiva, tento ir pra um lado e ir pro outro... daí tem coisas da infância que eu não suporto, mas me atingem muito... por que as coisas têm que me atingir tão diretamente ao ponto de eu perder a cabeça... por que sou assim?" 
O que interessa à psicanálise não é a palavra objeto da linguística. A psicanálise pretende, diferentemente, operar sobre a condição de abertura da significância, tal qual observamos com os provérbios e as locuções (LACAN, 1973c/1985). Nessa perspectiva, Elisa se mostra pronta para que o analista promova a interrogação do significante, descolando o engano da predicação fixa que o significado denota.

Elisa, logo de início, não se mostra mais interessada na sua condição orgânica, centrando-se em questões relacionais, oscilando entre uma postura queixante/ submissa ("eu não posso fazer nada e eles não me entendem”), e uma atitude mais implicada, reveladora de seu estado de alienação que desnuda seus limites na sustentação do desejo: "eu voltei a estudar, mesmo sem meu marido querer... eu não me sujeito mais a ele, mas é difícil, às vezes não tenho vontade de ir pra ficar esperando ele, não sei se gosto mesmo de estudar", ou ainda: "não aguento meu marido, ele não me entende, eu não quero mais ele não, mas fico nervosa quando ele não chega, fico esperando aflita...”.

A alienação como uma das operações constituintes do sujeito deve ser ultrapassada com o trabalho analítico, é o que Lacan propõe, a partir de um de seus fundamentos teóricos e clínicos: o inconsciente é o discurso do Outro (LACAN, 1964d/1998). Com efeito, quem fala, de início, é o Outro que sustenta a ordenação simbólica na qual o sujeito se insere, e da qual depende sua sobrevivência inicial.

Enquanto esse Outro fala, ao sujeito se impõem efeitos que o constituem e, também, necessidades que apontam para a satisfação da demanda do Outro, as quais se cristalizam numa rede de identificações que aprisiona o sujeito ao desejo do Outro.

Nessa via, Batista (1996) define a saúde mental como sendo o que garante o silêncio do Outro. No silêncio, o sujeito pode responder ao universal da norma com o particular do seu desejo, lidando com o mal-estar que lhe é inerente de forma criativa e responsável. Tal condição é diferente de ajustar o desejo à norma, oferecendo-lhe uma ortopedia, submetendo-o no sentido de restaurar ou instaurar um estado de "acomodamento" transitório.

Com efeito, é interessante destacar a avaliação feita por Elisa de seu tratamento anterior: "ele falava coisas para eu pensar, mas eu não entendia muito bem”. Acha que não foi “...ajudada, não mudou nada, nada”, queixando-se dos silêncios do psicólogo que a atendeu: "muitas vezes ele não falava nada, ficava lá, quieto, me olhando... acho que esperando”.

Naquilo que narra, Elisa consegue com facilidade se colocar de modo próprio, desnudando suas experiências que parecem mais próximas de um processo de implicação com a própria história, uma vez que não mostra resistência às pontuações da analista que pretendem dirigir a entrevista para verificar o lugar do sujeito frente às queixas (A: Não há nada que você possa fazer? Elisa: 
“Quase nada, sou alérgica a quase tudo”. A: Quase tudo... Elisa: “É — ri —, eu gosto de enfermagem, cuidar das pessoas, eu podia estudar isso mas não tenho ânimo...”).

Elisa também mostra os efeitos de seu tratamento quando transforma seus sintomas em questões: “...por que não cuido das minhas coisas ao invés das coisas dos outros? ...meus irmãos não são assim, minha irmã não se afeta tanto como eu com minha mãe, por que isso acontece comigo ?... eu quero saber disso, porque eu quero mudar algumas coisas, meu jeito com meu marido, achar alguma coisa que eu goste e aguente fazer".

Nessa via, chama a atenção, na entrevista de Elisa, a presença de um discurso sobre si que se endereça ao trabalho analítico e surge de pronto com as intervenções de quem dirige a entrevista, de maneira diferente das outras realizadas com pacientes iniciantes no tratamento.

Nestas, a fala queixante impera, com uma clara solicitação de resolução de problema que se mantém pela entrevista toda. A tentativa da analista em abrir o discurso, forçar a abertura da significância é inoperante, ao contrário do que se observa com Elisa, por exemplo, quando aparece uma configuração discursiva reveladora de uma construção que vincula a própria historicidade com a insatisfação presente na vida.

\section{CONCLUSÃO}

Neste trabalho optamos pela apresentação do caso que favorece a verificação da técnica proposta. Entendemos ser suficiente a indicação da diferença quanto às outras produções. Nos casos novos, ocorre certa homogeneização do discurso: atribuições universais de sentido sobre si, o médico, o mundo e, em alguns, uma quase incapacidade associativa, isto é, um discurso incapaz de um deslizamento metonímico.

Essas produções se conformam à modalidade de respostas encontradas em anamneses, no sentido de uma descrição dos fatos acrescida de uma catalogação de queixas. Tal diferença discursiva entre Elisa e os casos novos nos permitiram tecer algumas considerações.

A transferência, em Elisa, evidenciada pela abertura na significância, nos permite concluir que um analista, ofertando os dispositivos específicos à prática clínica, num modelo tangente à experiência do tratamento, favorece a abordagem dos seus efeitos sem a descaracterização da experiência. Assim, num recorte do tempo de tratamento, podemos formalizar os efeitos de algo referente à especificidade do tratamento, ao seu "meio".

Elisa não percebe alterações em seu quadro com o tratamento anterior, chegando a criticar o "modelo de trabalho". Ora, numa perspectiva de melhora 
sintomática e adaptativa, podemos dizer, corroborando Elisa, que não há uma alteração em seu posicionamento subjetivo que dirija alguma mudança de atitude frente às suas questões existenciais.

Por outro lado, algo parece ter se dado; algo que leva Elisa ao retorno e à continuidade do tratamento, como também ao questionamento quanto à sua parte na desordem de que se queixa, revelando um importante efeito na direção do que se espera com um tratamento psicanalítico, isto é, implicação e responsabilidade no mal-estar de que se queixa.

Com esse "novo" tratamento, referido por Elisa como melhor ("eu entendo mais o que essa psicanalista, é psicanalista que chama, né... parece que tá mais fácil que da outra vez...), é possível que ela promova alterações em sua vida prática a partir de um outro lugar subjetivo a ser encontrado com o tratamento — agora com a nomeada "psicanalista”- condição mais possível no momento, levando-se em conta os efeitos da intervenção anterior.

Para as nossas finalidades, Elisa vem mostrar que os efeitos de uma intervenção psicanalítica são passíveis de ser demonstrados e transmitidos, recortados num tempo, guardando-se, tal qual a especificidade da experiência analítica, a impossibilidade de se falar de tudo, do todo, mas nem por isso necessitando se alinhar com o inefável. Apostamos na análise da estrutura do discurso enquanto reveladora da presença da ação do analista, no sentido de uma produção de saber pelo sujeito, que cause a alteração de sua posição diante da trama que narra no início e, depois, com o término do tratamento.

Recebido em 19/11/2008. Aprovado em 7/6/2009.

\section{REFERÊNCIAS}

BATISTA, M.C.D. (1996) Psicanálise aplicada à saúde mental ou custo-efetividade. Correio Escola Brasileira de Psicanálise, v.15, São Paulo, p.30-36.

BRASIL. ( 2005) Ministério da Saúde. Secretaria de Atenção à Saúde. Dape. Coordenação de Saúde Mental. Reforma Psiquiátrica e política de saúde mental no Brasil. Documento apresentado à Conferência Regional de Reforma dos Serviços de Saúde Mental. Opas. Brasília, nov, 2005.

BUENO, D.S. e PEREIRA, M.E.C. (2002) Sobre a situação analítica: a experiência da psicoterapia psicanalítica no Hospital Universitário da Unicamp. Revista Pulsional, v.XV, n. 157, São Paulo, pp.15-24.

DUNKER, C.I. (2005) Leitura cruzada dos seminários 10 e 15, de Jacques Lacan, in "Seminário aberto", oferecido no Instituto de Psicologia da USP, São Paulo.

EIZIRIK, C.L. (2001) Processos possíveis de avaliação da psicanálise. Rev. Bras. Psicanálise, v.35, n.3, 2001, p.495-501. 
FIGUEIREDO, A.C. (1997) Vastas confusões e atendimentos imperfeitos: a clínica psicanalítica no ambulatório público (2 $2^{\mathrm{a}}$. ed). Rio de Janeiro: Relume-Dumará.

FONAGY, P. (2003) “Apanhar urtigas e mancheias, ou porque a pesquisa psicanalítica é tão irritante”, in: GREEN, A. (Org.) Psicanálise contemporânea. Rio de Janeiro: Imago.

FREUD, S. (1987) Edição standard brasileira das obras psicológicas completas de Freud. Rio de Janeiro: Imago.

(1913) “Sobre o início do tratamento”, v.XII, p.164-192.

(1926) “A questão da análise leiga”, v.XX, p. 214.

LACAN, J. (1964a/1998) “A excomunhão”, in Seminário 11: os quatro conceitos fundamentais da psicanálise. Rio de Janeiro: Jorge Zahar.

(1964b/1998) “A presença do analista”, in: Seminário 11: os quatro conceitos fundamentais da psicanálise. Rio de Janeiro: Jorge Zahar.

. (1964c/1998) “A rede dos significantes”, in: Seminário 11: os quatro conceitos fundamentais da psicanálise. Rio de Janeiro: Jorge Zahar.

(1964d/1998) "O inconsciente freudiano e o nosso", in Seminário 11: os quatro conceitos fundamentais da psicanálise. Rio de Janeiro: Jorge Zahar.

(1973a/1985) “O saber e a verdade”, in Seminário 20: mais, ainda. Rio de Janeiro: Jorge Zahar.

. (1973b/1985) “O amor e o significante”, in Seminário 20: mais, ainda. Rio de Janeiro: Jorge Zahar.

. (1973c/1985) “A Jakobson”, in Seminário 20: mais, ainda. Rio de Janeiro: Jorge Zahar.

MORETTO, M.L.T. (2001) O que pode um analista no hospital? São Paulo: Casa do Psicólogo.

Claudia Maria de Sousa Palma

claupalma@uol.com.br

Luciane Loss Jardim

lulossjardim@uol.com.br

Iza Maria de Oliveira

iza.maria.oliveira@uol.com.br 